\title{
Role and Value of Learning Theories in the Area of Adaptive Educational Hypermedia Systems Incorporating Learning Styles
}

\author{
https://doi.org/10.3991/ijet.v13i01.7614 \\ Xanthippi Tsortanidou( $\left.{ }^{\bowtie}\right)$, Charalampos Karagiannidis \\ University of Thessaly, Volos, Greece \\ xanthippi.tsortanidou@gmail.com \\ Adamantios Koumpis \\ Universität Passau, Passau, Germany
}

\begin{abstract}
The purpose of this study was to investigate the pedagogical basis of Adaptive Educational Hypermedia Systems (AEHS) that incorporate Learning Styles concerning learning paradigms and learning theories through a meticulous review of the relevant published work. We investigated twenty (20) AEHS and analyze them comparatively to a variety of adaptivity determinants. Two are the pivotal points that are crucial in exploration of pedagogical approaches of these systems: the locus of control and the provided learning material. We conclude that these systems are based mostly on the learning paradigm of Cognitivism and Constructivism. In addition, we assume that the concept of learning theory is not such a narrow term, given that networked world imposes the concept of personal learning.
\end{abstract}

Keywords-AEHS, learning paradigms, learning theories

\section{$1 \quad$ Introduction}

The relationship between learning theories and technologies can be concluded in some points, as are highlighted by Lowyck [1]: development of education affects the selection and use of learning theories and technologies; given the intricacy and variety of conceptualization, the relationship between learning theories and technology is asymmetric, as learning theories come before technology; learning theories and technologies are situated in a vague way; given the focal function of education to help learners obtain declarative, procedural and conditional knowledge, learning theories and technologies are "travel buddies" by leading to various conceptions of information processing and knowledge acquisition that influence the utilization of technology; learning theories and technologies are interconnected with information processing and knowledge acquisition, educational technologies shifted learner support from program/instructor control to shared and learner control and learning theories and relative conclusions represent an unclear combination of principles and applications. 
Instructional design theories offer prescriptive design principles that represent the optimal way for supporting users to learn and develop cognitive, emotional and physical aspects [2]. Berlanga \& García-Peñalvo [3] claim that instructional design theories are conceptualized from different points of view, namely traditional approaches which are considered objectivist and prescriptive approaches and their focus is on content and learning outcomes, constructivism approaches which facilitate learners to construct knowledge through learning activities and ultimately, novel approaches which aim at provision of models in order for solving problems in the description of learning designs by including practices from experts.

As far as studies that examine learning theories are concerned, it is noteworthy that [4] mention them, including systems from 1994 to 2003 and [5] discern five approaches to adaptive instruction and refer corresponding systems: macro-adaptive instruction, aptitude-treatment interactions (ATI-based), micro-adaptive instruction, including intelligent tutoring systems (ITSs), the adaptive/adaptable hypermedia/Web-based systems (AHS) and specific pedagogy-centered systems. Some researchers attempt to classify systems into categories that are belong to paradigms, such as CSCL, ITS, CAI Paradigms, etc. ([5], [6], [1]). In our study, we utilize the criterion of locus of control, full or partial learner, or program control as an significant indication of learning paradigm category and supplementary, the provided learning material inform as about the employed learning theories. We categorize AEHS by learning paradigms, instructional design theories and learning theories, some of which are explicitly referred by the authors and others are implied.

\section{Significance of the study}

Adaptive Educational Hypermedia Systems (AEHS) are a special type of WebBased Educational Systems that aim to personalize the content, its presentation and navigation to the needs and preferences of the individual user. In order to achieve customization of interaction, AEHS use mostly learner's domain knowledge, background and preferences as baseline [7]. Another source of information that is utilized for adaptation are learning style preferences. De Oliveira \& Fernandes [8] claim that the instructional design theories or learning theories are not commonly source of information for adaptation in AEHS. Therefore, they hypothesize that the use of instructional design or learning theories could be added as such. Besides the presentation and navigation adaptation, the instructional design theory that is more suited to the learner's learning style could be chosen [8]. Table 1 represents the variables that are exploited for adaptation in AEHS incorporating learning styles and as can be seen from the table below, instructional design theories or learning theories are not included among them. 
Table 1. Adaptivity determinants of AEHS incorporating Learning Styles

\begin{tabular}{|l|l|}
\hline $\begin{array}{c}\text { Encountered variables for adaptation/ } \\
\text { Adaptivity Determinants }\end{array}$ & \multicolumn{1}{c|}{$\begin{array}{c}\text { AEHS incorporating Learning Styles } \\
\text { from 1996 to 2013 }\end{array}$} \\
\hline Learning style & $\begin{array}{l}\text { CS383, iWeaver, FEIJOO.NET, INSPIRE, LSAS, MOT, } \\
\text { TANGOW, WHURLE, MASPLANG, DEUS, PALS2, AHA! } \\
\text { (3.0), AEHS-LS, MATHEMA, AMDPC, LS-AEHS }\end{array}$ \\
\hline Knowledge level/progress & $\begin{array}{l}\text { Arthur, ILASH, INSPIRE, AES-CS, TANGOW, } \\
\text { MASPLANG, PALS2, AEHS-LS, MATHEMA }\end{array}$ \\
\hline User (Web) experience & iWeaver, TANGOW, MATHEMA \\
\hline Cognitive style & AES-CS, AMDPC \\
\hline Learning goal & INSPIRE, MATHEMA \\
\hline Navigational choice & iWeaver \\
\hline Time spent & INSPIRE \\
\hline Language & TANGOW \\
\hline Instructional strategy & Arthur, TANGOW \\
\hline Preference for feedback & MATHEMA \\
\hline Groups of users & MATHEMA \\
\hline Last login & INSPIRE \\
\hline Preference for the kind of navigation & MATHEMA \\
\hline Age & TANGOW \\
\hline Favourite pages & INSPIRE \\
\hline User actions & TANGOW \\
\hline
\end{tabular}

\section{$3 \quad$ Big data on learning science}

An interesting and noticeable statement is that of Anderson: "Forget taxonomy, ontology, and psychology. Who knows why people do what they do? The point is they do it, and we can track and measure it with unprecedented fidelity. With enough data, the numbers speak for themselves" [9:2]. Society cope with the challenge presented by "big data", "datasets whose size is beyond the ability of typical database software tools to capture, store, manage and analyze" [10:1]. The increase of big data in education reflects the ongoing development of online education [11]. Learning Analytics (LA) utilize data that are gathered during the learner's eLearning experience -may include "big data"- and provide instructors and learners with "actionable intelligence" [12].

More specifically, Educational Data Mining (EDM) is an emerging research area that is related to Intelligent Tutoring (ITS) and Adaptive Educational Hypermedia System (AEHS). These systems are an alternative to the "just-put-it-on the-web approach" by personalizing learning to the needs of each student [13]. Personalizing education to each student is one of the greatest advantages of technology and big data help instructors do it [14]. Towards this direction, user traits, including motivation, satisfaction, learning styles, affective status, etc. and learning behavior are considered automatically by data mining so that student models are constructed [13]. There is a vague issue regarding the relationship among learning theories, knowledge, cognition 
and teaching and LA. Learning Analytics are considered pedagogically neutral but can utilized in order to evaluate the effectiveness of pedagogical strategies. From this perspective, LA are pedagogically oriented, as technologies that support educational settings are not pedagogically neutral, but impact on the analytics process. Thus, LA are implicitly pedagogical. At this point learning is translated into numbers. Learning behavior, several pedagogical factors and learning theories affect data which inform instructors and/or system in order for making appropriate instructional adjustments and interventions, based on user's performance. Therefore, LA could have predictive power over educational process and practice [12].

\section{Shift in Learner Support: Shift in Learning Paradigm}

Till the early nineties, adaptive instructional systems focused mainly on the acquisition of knowledge and skills and the detection of errors and misconceptions. Traditional hypermedia systems are nonadaptive, as they provided the same educational material to all learners and have been described as "user neutral" because they do not take the characteristics of each user into consideration [15]. Researchers take advantage of the technological features of Information and Communication Technologies for the design and development of such systems, without concentrating on pedagogical principles [16]. Therefore, some researchers began to criticize ITSs and other computer-based systems for their restricted adaptability of teaching actions compared to human teachers. Duchastel (1992) criticized them as a "nonpedagogical technology" (as cited in [5]). In contrast to the instructionist approach of these systems, Adaptive Hypermedia Systems are adapted specifically to each user. In the late nineties, researchers began to employ more complex pedagogical approaches, such as metacognitive strategies, collaborative learning, contingent learning strategies, constructivist learning, and motivational competence in these systems [5]. This shift in more complex pedagogical approaches reflects the transition from instructional programs that follow program-based guidance to learning environments and subsequently, brings a shift in the locus of control, from system to learner [17]. The adaptive systems aim at the optimization of the adaptation process, because they cannot be intelligent enough to suitably be adapted in all possible instances. Therefore, adaptive systems are expected to be controllable by the users and the amount of learner control seems to be a pivotal variable in these systems [18]. According to [19], the locus of control can be sorted into external (program control), internal (learner control) or shared. We adopt this classification for AEHS systems, as we can see at the Table 2. In addition to this, Table 3 shows the instructional decisions that can be taken by learners.

As far as the instructional approaches are concerned, the shift in locus of control affects them, including the transition from prescriptive to constructivist approaches. Prescriptive approaches support learners with structured educational material and guidance in order for acquiring knowledge, skills and attitudes, with the aim to advice, not directing them, whereas constructivist approaches view learners as responsible for their acquisition of knowledge, skills and attitudes and are provided with indi- 
vidualized support [4]. A central point in discussion about the relation between education and technology is how technology should support learners and/or groups in order for reach the learning goals. Different levels of support depend on learning theories and technological tools in learning environments, whereas open-ended learning environments offer learners nearly complete control over their learning. This reveals a change in view of the learning through the provided kind of support [1].

It is important to note that there is an interplay between learning styles and learner or program control. The Witkin's Cognitive Style Model is a representative instance of it, as in terms of control features, FI (Field Independent) learners prefer to control the system, while FD (Field Dependent) learners are more comfortable when they are guided by it. Therefore, an adaptive system should provide FI learners with learner control option and FD with program control option [20]. For instance, AES-CS offers a learner control option for FI users and a program control option for FD ones. FI users are provided with menu in order to choose the course in any order, while FD users are not provided with menu but the system guides them via adaptive navigation support [18]. Provided that learning theories and relative principles are dependent on developments in technology, we refer a short overview of learning theories and related IT paradigms below.

Table 2. Learner support in AEHS incorporating Learning Styles

\begin{tabular}{|c|c|c|c|c|c|c|c|c|c|c|c|c|c|c|}
\hline $\begin{array}{l}\text { Learner Con- } \\
\text { trol }\end{array}$ & $\begin{array}{l}\infty \\
\infty \\
0 \\
0 \\
0\end{array}$ & $\stackrel{\Xi}{E}$ & לूँ & 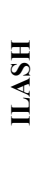 & $\frac{\underline{\underline{n}}}{\underline{\underline{\alpha}}}$ & 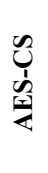 & 先 & 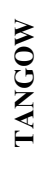 & 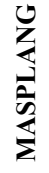 & 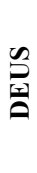 & 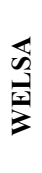 & 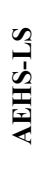 & 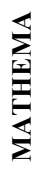 & $\sum_{4}$ \\
\hline Internal & & & $\mathrm{X}$ & & $\mathrm{X}$ & $\mathrm{X}$ & & & & & & & $\mathrm{X}$ & \\
\hline Shared & $\mathrm{X}$ & & $X$ & & $\mathrm{X}$ & & & $X$ & & & $\mathrm{X}$ & & & \\
\hline External & & $\mathrm{X}$ & & $\mathrm{X}$ & & $\mathrm{X}$ & $\mathrm{X}$ & & $\mathrm{X}$ & $\mathrm{X}$ & & $\mathrm{X}$ & & $\mathrm{X}$ \\
\hline
\end{tabular}

Table 3. Learners' Instructional Decisions over AEHS incorporating Learning Styles

\begin{tabular}{|c|c|c|c|c|c|c|c|c|}
\hline Instructional decisions & $\begin{array}{l}\infty \\
\infty \\
0\end{array}$ & $\begin{array}{l}\dot{\Xi} \\
\sum_{0}^{ \pm}\end{array}$ & 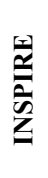 & 己ֶ & 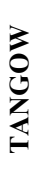 & 峉 & $\frac{\sum_{i=1}^{\mathbb{Z}}}{\sum}$ & 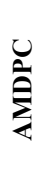 \\
\hline Selection of content & & & $\mathrm{X}$ & & & & & $\mathrm{X}$ \\
\hline Choosing a learning path & & & $\mathrm{X}$ & $\mathrm{X}$ & & $\mathrm{X}$ & & \\
\hline Choosing hypermedia tools & $\mathrm{X}$ & & & & & & & \\
\hline Choosing media experiences & & $\mathrm{X}$ & & & & & & \\
\hline Changing the knowledge level (content) & & & $\mathrm{X}$ & & $\mathrm{X}$ & & $\mathrm{X}$ & \\
\hline Changing the learning styles feature (presentation) & & & $\mathrm{X}$ & & $\mathrm{X}$ & & & \\
\hline Deciding on the level of adaptation & & & $\mathrm{X}$ & & & & & \\
\hline Selection of learning goals & & & $\mathrm{X}$ & & & & $\mathrm{X}$ & \\
\hline Selection of instructional strategies & & & $\mathrm{X}$ & $\mathrm{X}$ & & & & \\
\hline
\end{tabular}




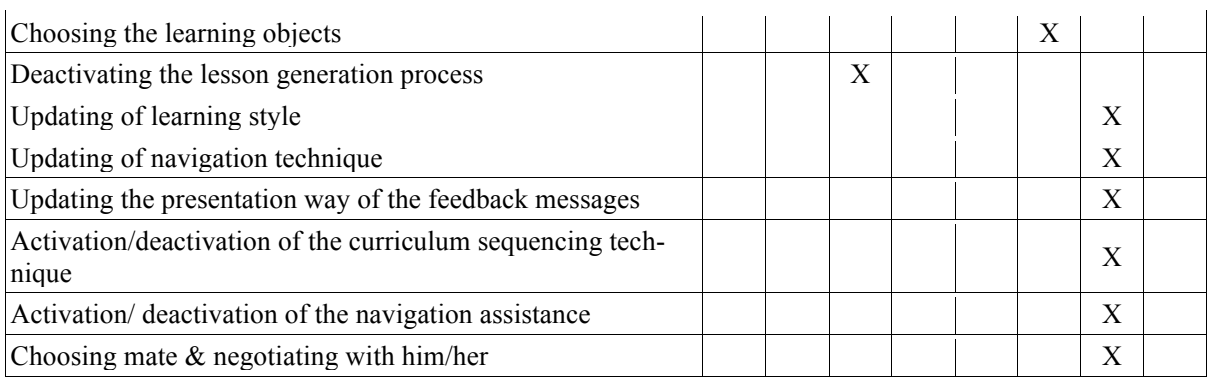

\section{Overview of the impact of pedagogical approaches on IT paradigms}

Traditional CAI programs is the oldest paradigm in IT and their focal concern is the instructional efficacy [6]. These programs provide learners with linear feedback that was criticized because of their lacking individual support and fragmented perspective. New generation of programs called Intelligent Computer-Assisted Instruction (ICAI) attempt to solve this lack. Although these systems are behavioristic since they exploit the status of student's behavior in order to adapt instruction, they offer maximal learning support through adaptive feedback (Urban-lurain, 1996 as cited in [1]).

\subsection{Cognitivist Paradigm and ITS (Intelligent Tutoring Systems)}

This paradigm is founded on the supposition that education could be globally ameliorated by providing every student with a personal tutor and on the gold standard of "one-on-one tutoring" (Lepper, et. al, 1993 as cited in [6]). The focal point of early cognitive learning theories is the problem-solving and information processing (Miller, et. al., 1960 as cited in [1]). Information processing theory focus on the load that is caused to a learner's cognitive system by tasks [21] and triggers the development of Cognitive Load Theory. For instance, cognitive-based learning use hypertext, hypermedia, and so forth [22]. From this viewpoint ITS is explicitly cognitive [1].

\subsection{Constructivist Paradigm and Computer-Enhanced Learning Environments}

While Information Processing depicts a mechanistic and computational view of learning and cognition, constructivist perspective represents learning as the creation of meaning based on "experience-in-context" (Duffy et al., 1993 as cited in [1]). From constructivist viewpoint, knowledge occurs as an active interplay between the learner and the learning environment through learner's cognitive structures, its pivotal point is the learning process and the issue of cognitive selforganization [23]. This paradigm perceives the learning environment as tutee not as tutor and shifts the focus from what is learned to how is learned [5]. The presumption here is that the learner obtains cog- 
nitive benefits through activities, beyond simply learning [6]. Constructivism as an umbrella term includes many perspectives and approaches, such as situated cognition, social negotiation and versions of open learning, such as discovery learning, problembased learning, inquiry learning, experiential learning and constructivist learning that offer nearly unlimited control to learners [24].

\subsection{Socio-Constructivist Paradigm and Contingent Teaching Systems}

Some researchers have highlighted the significance of peer interaction for cognitive development and this viewpoint of learning as a social, collaborative and constructive process is represented by Social Constructivism (Doise \& Mugny, 1984; Ernest, 1995 as cited in [6]). Within this context, a well-known theory is Vygotsky's Sociocultural Theory that offers an active role to the learner (D. Wood \& H. Wood, 1996 as cited in [5]). Vygotsky assumes a Zone of Proximal Development that represents the learner's potential capabilities, beyond the existing developmental level, by working with a more skilled peer or teacher. The evaluation of learners' previous knowledge also, is important to implementing contingent teaching strategy to computer-based adaptive instruction [5]. A relative theory to this socially oriented constructivist perspective of learning is represented by Russian researchers Leont'ev, Galperin and Rubenstein and its central characteristic is the role of activity in human development, called Activity Theory. These two theories are exploited in human/computer interaction by Computer Science [25], [6]).

\subsection{Motivational Paradigm}

Some novel Adaptive Instructional Systems take student motivation into consideration by developing Motivation-based Adaptive Systems ([26], [5]).

\subsection{Metacognitive Paradigm and Metacognition-Based Adaptive Systems}

Metacognitive skill is learners' understanding of their own cognitive processes and researchers argue that in addition to this, the control of it plays a key role in the learning [5]. However, metacognitive support in order for developing metacognitive thinking skills is lacking and consequently, Metacognition-Based Adaptive Systems are nearly absent [27], [5]).

\subsection{Collaborative Paradigm and CSCL (Computer-Supported Collaborative Learning)}

There is a growing interest on collaborative learning which is assumed that guides to deeper learning, critical thinking and long term retention of the educational material by offering opportunities for developing social and communication skills ([28], [29], [4]). Social constructivism, sociocultural theories and situated cognition offer the background from which CSCL has emerged as a novel paradigm in instructional 
technology, namely the "collaborative learning" ([30], [6]). In these theories, learning is viewed as "a process of enculturation" [31:33]. This novel paradigm represents a transition in point of reference and pose as the object of study the learning within social and cultural context.

\subsection{Educational data mining under the scope of Emerging Pedagogical Approaches}

The triumvirate of motivation, metacognition and self-regulated learning (SRL) is an emerging pedagogical approach and challenge that provide researchers with important affordances to learning science and trigger them to inquire why and how learners develop knowledge, beliefs, attitudes and interests. As far as educational data mining is concerned, namely the field that engages with automated analysis of educational data, can play a major role on research about motivation, metacognition and self-regulated learning because of analyzing student trajectories [32].

\section{AEHS incorporating learning styles: pedagogical approaches}

\subsection{Issue of Learning Paradigms}

From the aforementioned analysis, it is easy to see that the locus of control whether assigned to the learner, shared between them or assigned to the system- is a crucial point, as reveals the role of the learner -active or passive- and consequently, the level of adaptation:

- If the locus of control lies with the user, then the user takes instructional decisions and this means that the system follows the constructivist viewpoint in learning.

- If the user participates in groups in order to accomplish activities, discusses or communicates with peers, then the system follows the socioconstructivist/collaborative viewpoint in learning.

- If the users assess their own learning process, then the system adopts metacognitive orientation and if the system takes motivation into consideration as adaptive variable in adaptation process, then it follows the motivational paradigm. Table 4 presents the Learning Paradigms that are followed by the AEHS systems. It is noteworthy to say that in some systems, such as MOT, TANGOW, WHURLE and AHA! (3.0), authors do not refer explicitly that follow the Cognitivist Paradigm but we imply it as, according to [22], cognitive-based learning uses hypermedia.

\subsection{Issue of learning theories}

It is noteworthy to say that there is an ambiguity between the terms "learning theory" and "instructional design theory". Tennyson claims that "instructional theories offer direct transitions between learning theory, instructional theory, and instructional design process and methodology" [33:8]. We perceive the term "learning theory" as 
Table 4. Learning Paradigms that are followed by the AEHS incorporating Learning Styles

\begin{tabular}{|c|l|}
\hline Learning Paradigm & AEHS \\
\hline Behaviorist & CS383, Arthur, iWeaver, ILASH, MASPLANG, PALS2, AEHS-LS \\
\hline Cognitivist & $\begin{array}{l}\text { CS383, Arthur, iWeaver, ILASH, FEIJOO.NET, INSPIRE, AES-CS, LSAS, } \\
\text { MOT, TANGOW, WHURLE, MASPLANG, DEUS, PALS2, AHA! (3.0), } \\
\text { WELSA, AEHS-LS, MATHEMA, AMDPC, LS-AEHS }\end{array}$ \\
\hline Constructivist & $\begin{array}{l}\text { CS383, iWeaver, INSPIRE, LSAS, MASPLANG, PALS2, WELSA, } \\
\text { MATHEMA, } \\
\text { LS-AEHS }\end{array}$ \\
\hline Socio-Constructivist & CS383, INSPIRE, MASPLANG, WELSA, MATHEMA \\
\hline Motivational & MASPLANG, WELSA \\
\hline Metacognitive & INSPIRE, MATHEMA \\
\hline Collaborative & CS383, INSPIRE, MASPLANG, WELSA, MATHEMA \\
\hline
\end{tabular}

the theory that reflects the way people learn, while "instructional design theory" as the theory that apply learning theory. Sometimes, the two terms are referred interchangeably, but we attempt to discriminate them in our study in accord with learning paradigms that reflect their pedagogical orientation. For the categorization of these theories into learning paradigms, we based on several studies ([34], [28], [35]). We can observe from the Table 4 that the most AEHS are based on the learning paradigm of Cognitivism.

After 2005, authors combined intelligent tutoring and adaptive hypermedia technologies. One explanation why most systems based on Cognitivism is because there are many instructional design theories that offer principles in order for avoiding the cognitive overload of learner with information that is not well structure and/or unnecessary at hypermedia courseware and consequently, making the processing of information more difficult [34]. Such theories are Sweller's Cognitive Load Theory, Mayer's Cognitive Theory of Multimedia Learning, Paivio's Dual Coding Theory for multimedia learning. For example, Wolf [36] for the design of multimedia at iWeaver, he employs Paivio's Dual Coding Theory, Sweller's Cognitive Load Theory and Mayer's Cognitive Theory of Multimedia Learning in order to offer a combination of words and pictures, locating words near the corresponding pictures and uses animation and narrated text. Furthermore, AEH systems which are authored after 2007 implement not only Cognitivism, but also Constructivism. This means that authors are interested in both presentation of information and approach of learning as an active and constructive process, by providing appropriate content and corresponding instructional strategies. Apart from the reported learning theories by authors, we attempt to investigate the learning theories that are implied by the provided educational material and the corresponding adaptation rules that reflect the instructional methods (Table 5).

We analyze the systems whose description allows us to infer the learning and instructional design theories that are based on. We do not refer learning theories about the adaptive hypermedia TANGOW, AHA! 3.0 and MOT because they are generalpurpose systems and therefore educational materials are developed by authors. We attempt to "extract" learning theories that are embodied in educational material, such as Gardner's Theory of Multiple Intelligences, Gagne's Conditions of Learning Theo- 
ry, Meaningful Verbal Learning Theory, etc. More specifically, INSPIRE, CS383, AMDPC, LS-AEHS MASPLANG and MATHEMA follow similar lesson structure, namely, presentation of theory, example and practice but the order of them can be changed according to learning styles, as we can see especially at INSPIRE, MATHEMA and LS-AEHS. Therefore, we can assume that these systems are supported by the Tennyson \& Rasch's Linking Theory who propose instructional prescriptions (expository, practice, problem-oriented, etc.) in accordance with learners' needs. The remaining systems also apply this theory, but the instructional prescriptions are not as evident as in the above systems [33]. Another theory that is obviously followed by the systems, is Gagne's Conditions of Learning Theory. Gagne (1984) propose five categories of learning (a) intellectual skills (procedural knowledge), (b) verbal information (declarative knowledge), (c) cognitive strategies (executive control processes), (d) motor skills, and (e) attitudes. Some of them are applied by the systems, such as CS383, MASPLANG, iWeaver, AMDPC, AEHS-LS, LSAS, WELSA (b), iWeaver (d). It is remarkable that the second category coincides with the linguistic intelligence of Gardner's Theory of Multiple Intelligences [37].

Table 5. Learning Paradigms, Instructional Design Theories and Learning Theories of AEHS incorporating Learning Styles

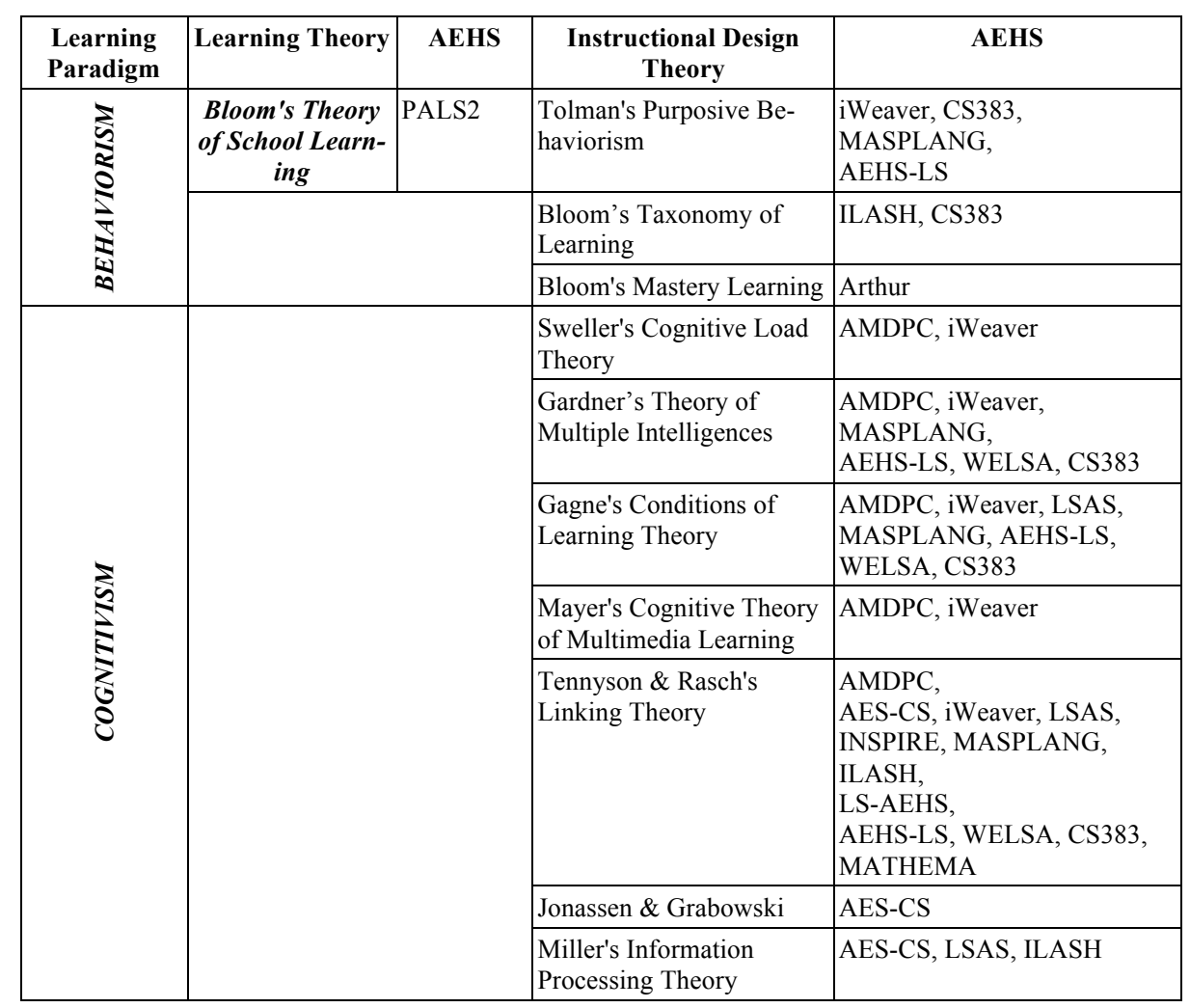




\begin{tabular}{|c|c|c|c|c|}
\hline & & & $\begin{array}{l}\text { Paivio's Dual Coding } \\
\text { Theory }\end{array}$ & iWeaver, DEUS \\
\hline & & & $\begin{array}{l}\text { Pask's Conversation } \\
\text { Theory }\end{array}$ & LSAS \\
\hline & & & $\begin{array}{l}\text { Reigeluth \& Stein's Elabo- } \\
\text { ration Theory }\end{array}$ & INSPIRE \\
\hline & & & Gagné's Cognitive Theory & INSPIRE \\
\hline \multirow{5}{*}{ 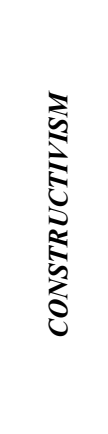 } & $\begin{array}{l}\text { Knowles's Andra- } \\
\text { gogy }\end{array}$ & iWeaver & $\begin{array}{l}\text { Spiro et al.'s Cognitive } \\
\text { Flexibility Theory }\end{array}$ & iWeaver \\
\hline & $\begin{array}{l}\text { Adult Learing } \\
\text { Theory }\end{array}$ & INSPIRE & $\begin{array}{l}\text { Ausubel's Meaningful } \\
\text { Verbal Learning Theory }\end{array}$ & IWeaver, CS383 MASPLANG \\
\hline & $\begin{array}{l}\text { Kolb's Experien- } \\
\text { tial Learning } \\
\text { Theory }\end{array}$ & $\begin{array}{l}\text { MATHEM } \\
\text { A }\end{array}$ & $\begin{array}{l}\text { Merrill's Component } \\
\text { Display Theory }\end{array}$ & INSPIRE \\
\hline & $\begin{array}{l}\text { Bruner's Discov- } \\
\text { ery Learning } \\
\text { Theory }\end{array}$ & $\begin{array}{l}\text { INSPIRE, } \\
\text { CS383 }\end{array}$ & Lave's Situated Learning & INSPIRE, MATHEMA \\
\hline & & & $\begin{array}{l}\text { Rogers' Experiential } \\
\text { Learning }\end{array}$ & INSPIRE, MATHEMA \\
\hline 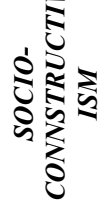 & $\begin{array}{l}\text { Collaborative } \\
\text { learning }\end{array}$ & $\begin{array}{l}\text { INSPIRE } \\
\text { MATHEM } \\
\text { A CS383 } \\
\text { WELSA } \\
\text { MASPLA } \\
\text { NG }\end{array}$ & & \\
\hline
\end{tabular}

Therefore, systems that include verbal/auditory learning preference apply this theory, such as CS383, MASPLANG, WELSA, iWeaver, AMDPC, AEHS-LS through games, animations, movies, audiovisual materials, etc. Moreover, another instructional theory that we meet is Ausubel's Meaningful Verbal Learning Theory [38]. Systems, such as iWeaver, CS383 and LSAS provide users with advance organizers and overviews that conclude main concepts. Lave's Situated Learning [31] is applied in technology-based learning activities, focus on problem-solving activities and requires social interaction and collaboration. So, we assume that INSPIRE and MATHEMA apply Situated Learning, as they offer problem-solving activities in the context of collaboration. In addition to this, MATHEMA, INSPIRE, WELSA and CS383 offer discussion/work in teams and group activities. As a consequence, Collaborative Learning is applied by them, that is stressed by Vygotsky in the context of "Zone of Proximal Development" (ZPD), namely the gap between what learners could achieve on their own and what they could achieve in cooperation with others [39]. Furthermore, Bruner's Discovery Learning Theory is applied by MATHEMA and INSPIRE, as they support real-life problems, guided by discovery and exploration. Miller's Information Processing Theory [40] is applied by AES-CS, ILASH and LSAS, as they provide users with information in chunks for processing and Tolman's Purposive Behaviorism applied by CS383, MASPLANG, AEHS-LS, iWeaver, as they offer cognitive maps. Finally, INSPIRE and MATHEMA offer self-assessment exercises, applying Rogers' Experiential Learning [41]. 


\section{$7 \quad$ Learning theory or learner's theory?}

The instructional design or learning theory is used in association with user's profile that includes domain knowledge, background, preferences and learning styles as source for adaptation in AEHS. However, a troublesome issue is that Adaptive Educational Hypermedia Systems do not implement learning theories explicitly. It is remarkable that AEHS focus on satisfaction of user's needs instead. Considering that the aim of these systems is personalization, several aspects of them should be customized to users' traits and needs.

Therefore, personalization guarantees, in a sense, the implementation of personalized learning theory or better a "learner's theory". From this educational perspective, the learner is not only the locus of control, but also the locus of adaptation and thus, her/his traits are source of adaptation and personalization. AEHS may apply a distinctive implementation of individualized learning theory, a "learner's theory" which is a unique instructional situation based on each user's profile. The concept of learning theory is dependent on user's profile and needs, by broadening it and extending from learning to learner's learning.

In addition to this, several studies have demonstrated that Behaviorism, Cognitivism, and Constructivism were developed in a time when learning was not influenced by technology. Despite the fact that learning occurs both inside and outside the person in the networked world, these theories adopt the principality of the individual in learning. The process of learning is the focus of learning theories, not the value of what is learned, while the manner of acquisition of information is worthy in the networked world. Therefore, learning is a process that occurs not totally under the learner's control, but resides also outside the person, namely in nonhuman appliances. This means that learning connects information and these connections enable individuals to learn. In terms of knowledge economy, the competence to see and form connections, construct information patterns and utilize the information flow is a key skill, as impact on our personal learning. What is more, the capability to distinct useful from useless information is a crucial task and consequently, decision-making is a learning process. The criticism of usefulness of learning something or not is a meta-skill. According to abovementioned, a new learning theory comes out named Connectivism in the networked world. The Connectivism starts from the individual and integrates principles of chaos, network, complexity and self-organization theories. Personal knowledge can be considered as a loop around the network, the individual, the network and then, learning is provided to individual. Connectivism highlights the amplification of learning through the extension of a personal network [42].

\section{Conclusion}

Big Data, new Learning Analytics and ensemble approaches signal a new era of educational systems and especially those that offer adaptivity with respect to the learning style they offer. However, and despite a well-established corpus of literature in the areas of learning theories, we also see that an argument that appeared some 
years ago and which at that point was rather provocative, it is now rather well timed: Anderson [9] introduced the idea of "the end of theory" where the over-supply of data "makes the scientific method obsolete"; in his article Anderson also mentions in the opening the well-known aphorism of [43] namely that "all models are wrong, but some are useful". From this viewpoint, instructors should develop a data-driven culture of using data that inform decision-making in educational practice [44].

The main aim of this work is to provide an overview of the pedagogical approaches employed to address the field of AEHS systems that incorporate learning styles. This refers mainly to learning paradigms, learning theories and instructional design theories employed or used to ground or support the implementation of a particular AEHS system. We conclude that Cognitivism and Constructivism are the most commonly used learning paradigms. Although the interplay between learning theories and technologies has been highlighted and the learning theories could be exploited as adaptive variable in such adaptive learning environments, we determine that none of the aforementioned systems employ them as adaptivity determinant. In addition to this, we underline the relationship among learner or program control, learning theories and learning styles and consequently, their impact on the employed technologies. Future work could explore the possibility to utilize learning theories as determining adaptation factor in the design of such systems. Apart from this, it is interesting to explore the pedagogical basis from a technological viewpoint, such as through the employed adaptive technologies and attempt to design adaptive educational systems in order for offering the administration of reusable learning objects to learners. Ultimately, regarding "big data", study about the factors that affect learners make choices over their learning experience could enrich learning theories and further, function as key indicators or predictors over the users' performance and their learning behavior [45].

\section{References}

[1] Lowyck, Joost. "Bridging Learning Theories and Technology-Enhanced Environments: A Critical] Appraisal of Its History." Handbook of Research on Educational Communications and Technology, 2013, 3-20.

[2] Reigeluth, Charles M. and Carr-Chellman, Alison. Instructional-design theories and models (volume II). A new paradigm of instructional theory, 1999.

[3] Berlanga, Adriana J., and Francisco José García-Peñalvo. "Learning design in adaptive educational hypermedia systems." J. UCS 14, no.22 (2008), 3627-3647.

[4] Papanikolaou, Kyparisia A., and Maria Grigoriadou. "Building an Instructional Framework to Support Learner Control in Adaptive Educational Systems." Advances in WebBased Education (n.d.).

[5] Park, Ok-choon, and Jung Lee. "Adaptive instructional systems." Educational Technology Research and Development 25 (2003), 651-684.

[6] Koschmann, Timothy. "Paradigm shifts and instructional technology: An introduction." CSCL: Theory and practice of an emerging paradigm (1996), 1-23.

[7] Brusilovsky, Peter. "Adaptive educational systems on the world-wide-web: A review of available technologies." Proceedings of Workshop" WWW-Based Tutoring" at 4th International Conference on Intelligent Tutoring Systems (ITS'98), San Antonio, TX. 1998. 
[8] De Oliveira, José M. Parente, and Clovis Torres Fernandes. "A framework for adaptive educational hypermedia system." WSS 2003 (2003), 55.

[9] Anderson, Chris. "The End of Theory: The Data Deluge Makes the Scientific Method Obsolete." Wired magazine 16, no.7 (2009), 16-07.

[10] Manyika, James, Michael Chui, Brad Brown, Jacques Bughin, Richard Dobbs, Charles Roxburgh and Angela Hung Byers. "Big Data: the next Frontier for Innovation, Competition, and Productivity." (2011).

[11] Ferguson, Rebecca. "Learning analytics: drivers, developments and challenges." International Journal of Technology Enhanced Learning 4, no. 5/6 (2012), 304. https://doi.org/10.1504/IJTEL.2012.051816

[12] Greller, Wolfgang and Hendrik Drachsler. "Translating Learning into Numbers: A Generic Framework for Learning Analytics." Educational Technology \& Society 15, no.3 (2012), 42-57.

[13] Romero, Cristóbal and Sebastián Ventura. "Educational Data Mining: A Review of the State of the Art." IEEE Trans. Systems, Man, and Cybernetics, Part C 40, no.6 (2010), 601-618.

[14] West, Darrell M, editor. Big Data for Education: Data Mining, Data Analytics, and Web Dashboards. Governance Studies at Brookings. 2012.

[15] Brusilovsky, Peter. "Methods and Techniques of Adaptive Hypermedia." User modeling and user-adapted interaction 6, no.2-3 (1996), 87-129. https://doi.org/10.1007/ BF00143964

[16] Mikropoulos, T. A. "On the pedagogy of open and distance learning systems." Department of Primary Education, University of Illinois, Hellas amikrop@ cc.uoi. Gr (2000).

[17] Chung, Jaesam, and Charles M. Reigeluth. "Instructional Prescriptions for Learner Control." Educational Technology 32, no.10 (1992), 14-20.

[18] Triantafillou, Evangelos, Andreas Pomportsis, and Stavros Demetriadis. "The design and the formative evaluation of an adaptive educational system based on cognitive styles." Computers E Education 41, no. 1 (2003), 87-103. https://doi.org/10.1016/S03601315(03)00031-9

[19] Corbalan, Gemma, Liesbeth Kester, and Jeroen J. Van Merriënboer. "Selecting learning tasks: Effects of adaptation and shared control on learning efficiency and task involvement." Contemporary Educational Psychology 33, no. 4 (2008), 733-756. https://doi.org/10.1016/j.cedpsych.2008.02.003

[20] Yoon, Gwan-Sik. "The Effects of Instructional Control, Cognitive Style, and Prior Knowledge on Learning of Computer-Assisted Instruction." Journal of Educational Technology Systems 22, no. 4 (1994), 357-370. https://doi.org/10.2190/8AVP-REQ0-HAHC$1 \mathrm{YJH}$

[21] Mayer, Richard E. "Learning with technology." Educational Research and Innovation, 2010, 179-198. https://doi.org/10.1787/9789264086487-10-en

[22] Cooper, Peter A. "Paradigm shifts in designed instruction: From behaviorism to cognitivism to constructivism." Educational technology 33, no.5 (1993), 12-19.

[23] Cobb, Paul. "Where Is the Mind? Constructivist and Sociocultural Perspectives on Mathematical Development." Educational Researcher 23, no. 7 (1994), 13. https://doi.org/10.3102/0013189X023007013

[24] Kirschner, Paul A., John Sweller, and Richard E. Clark. "Why Minimal Guidance During Instruction Does Not Work: An Analysis of the Failure of Constructivist, Discovery, Problem-Based, Experiential, and Inquiry-Based Teaching." Educational Psychologist41, no. 2 (2006), 75-86. https://doi.org/10.1207/s15326985ep4102 1 
[25] Kuutti, Kari. "Activity theory as a potential framework for human-computer interaction research." Context and consciousness: Activity theory and human-computer interaction 17, no.44 (1996).

[26] Du Boulay, Benedict, and Rosemary Luckin. "Modelling Human Teaching Tactics and Strategies for Tutoring Systems." International Journal of Artificial Intelligence in Education 12 , no. 3 (2001), 235-256.

[27] Clarebout, Geraldine, et al. "Animated pedagogical agents: An opportunity to be grasped?." Journal of Educational multimedia and hypermedia 11, no.3 (2002), 267-286.

[28] Reigeluth, Charles M. "What is instructional-design theory and how is it changing." Instructional-design theories and models: A new paradigm of instructional theory 2 (1999), 5-29.

[29] Van Merriënboer, Jeroen Jg, and Paul A. Kirschner. "Three worlds of instructional design: State of the art and future directions." Instructional Science 29, no.4 (2001), 429-441. https://doi.org/10.1023/A:1011904127543

[30] Noddings, Nel. "Theoretical and Practical Concerns about Small Groups in Mathematics." The Elementary School Journal 89, no. 5 (1989), 607-623. https://doi.org/10.1086/461595

[31] Brown, J. S., A. Collins, and P. Duguid. "Situated Cognition and the Culture of Learning." Educational Researcher 18, no. 1 (1989), 32-42. https://doi.org/10.3102/0013189X 018001032

[32] Winne, Philip H., and Ryan SJd Baker. "The potentials of educational data mining for researching metacognition, motivation and self-regulated learning." JEDM-Journal of Educational Data Mining 5, no.1 (2013), 1-8.

[33] Tennyson, Robert D. "Historical reflection on learning theories and instructional design." Contemporary Educational Technology 1, no.1 (2010), 1-16.

[34] Sorden, Stephen D. "A cognitive approach to instructional design for multimedia learning." Informing Science 8 (2005), 263-279. https://doi.org/10.28945/498

[35] Mergel, Brenda. "Instructional design and learning theory." (1998).

[36] Wolf, Christian. "iWeaver: towards' learning style'-based e-learning in computer science education." Proceedings of the fifth Australasian conference on Computing education-Volume 20. Australian Computer Society, Inc., (2003), 273-279.

[37] Gardner, Howard, and Thomas Hatch. "Multiple Intelligences Go to School: Educational Implications of the Theory of Multiple Intelligences." Educational Researcher 18, no. 8 (1989), 4. https://doi.org/10.2307/1176460

[38] Ausubel, David P. "The facilitation of meaningful verbal learning in the classroom1." Educational Psychologist 12, no. 2 (1977), 162-178. https://doi.org/10.1080/00461527709529171

[39] Warschauer, Mark. "Computer-Mediated Collaborative Learning: Theory and Practice." The Modern Language Journal 81, no. 4 (1997), 470. https://doi.org/10.1111/j.15404781.1997.tb05514.x

[40] Miller, George A. "The magical number seven, plus or minus two: some limits on our capacity for processing information." Psychological Review 63, no. 2 (1956), 81-97. https://doi.org/10.1037/h0043158

[41] Weibell, Christian J. (2011). "Principles of learning: 7 principles to guide personalized, student-centered learning in the technology-enhanced, blended learning environment". Accessed July 12, 2017. https: / / principlesoflearning.wordpress.com

[42] Siemens, George. "Connectivism: A learning theory for the digital age." (2014).

[43] Box, George E. "Science and Statistics." Journal of the American Statistical Association 71, no. 356 (1976), 791. https://doi.org/10.1080/01621459.1976.10480949 
Paper-Role and Value of Learning Theories in the Area of Adaptive Educational Hypermedia Systems...

[44] Romero, Cristobal, and Sebastian Ventura. "Data mining in education." Wiley Interdisciplinary Reviews: Data Mining and Knowledge Discovery 3, no. 1 (2012), 12-27. https://doi.org/10.1002/widm.1075

[45] Baker, R.S.J.d. "Data Mining." International Encyclopedia of Education, 2010, 112-118. https://doi.org/10.1016/B978-0-08-044894-7.01318-X

\section{Authors}

Xanthippi Tsortanidou holds a Master of Education on "Contemporary Learning Environments and Curriculum Development" and a Bachelor of Primary Education from the University of Thessaly, Greece. Her research interests are in the area of adaptive educational environments and in particular the exploration of pedagogical basis and the use of learning styles.

Charalampos Karagiannidis is Professor for ICT Applications in Learning \& Special Education at the Department of Special Education, University of Thessaly, Greece. His research interests are in the area of intelligent user interfaces and their use to improve access for people with disabilities. He had been one of the first to conduct research in what would be nowadays regarded as Big Data for human-computer interaction, with use of mixed research methods that make use of applied mathematics to improve decision making for improving quality of access to information.

Adamantios Koumpis is scientific collaborator at the Universität Passau, Lehrstuhl für Informatik mit Schwerpunkt Digital Libraries and Web Information Systems. Till June 2014 Adamantios was Research Fellow at the Digital Enterprise Research Institute of the National University of Ireland, Galway. Before this, Adamantios headed the Research Programmes Division of ALTEC Software S.A., which he founded in 1996.

Article submitted 23 August 2017. Published as resubmitted by the authors 14 October 2017. 